\title{
Annual Energy Savings and Peak Power Reduction Simulated for CCHP Design and Baseline HP in Cold Climate Cities - FY19 2rd Quarter Milestone Report
}

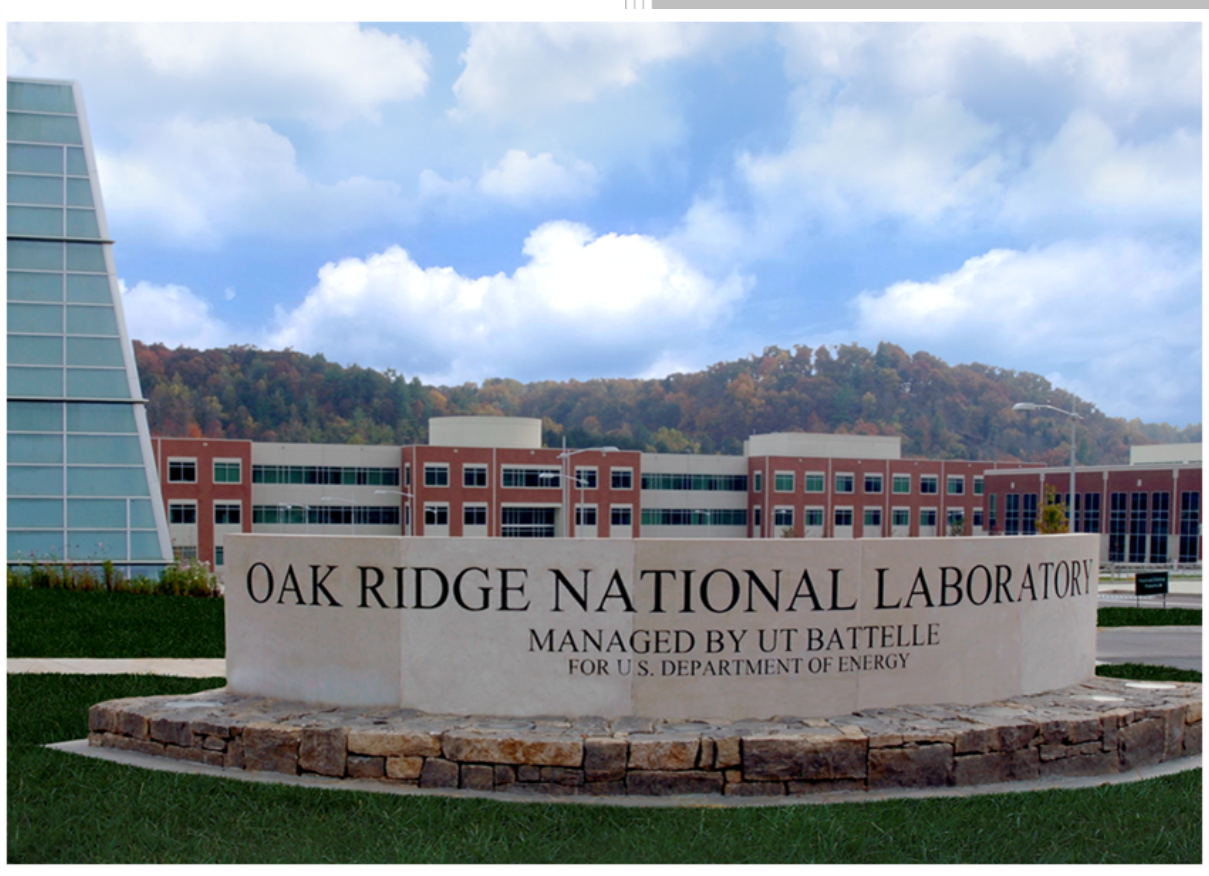

Approved for public release. Distribution is unlimited.

Bo Shen Jeffrey Munk 02/28/2019 


\title{
DOCUMENT AVAILABILITY
}

Reports produced after January 1, 1996, are generally available free via US Department of Energy (DOE) SciTech Connect.

Website http://www.osti.gov/scitech/

Reports produced before January 1, 1996, may be purchased by members of the public from the following source:

\author{
National Technical Information Service \\ 5285 Port Royal Road \\ Springfield, VA 22161 \\ Telephone 703-605-6000 (1-800-553-6847) \\ TDD 703-487-4639 \\ Fax 703-605-6900 \\ E-mail info@ntis.gov \\ Website http://www.ntis.gov/help/ordermethods.aspx
}

Reports are available to DOE employees, DOE contractors, Energy Technology Data Exchange representatives, and International Nuclear Information System representatives from the following source:

Office of Scientific and Technical Information

PO Box 62

Oak Ridge, TN 37831

Telephone 865-576-8401

Fax 865-576-5728

E-mail reports@osti.gov

Website http://www.osti.gov/contact.html

This report was prepared as an account of work sponsored by an agency of the United States Government. Neither the United States Government nor any agency thereof, nor any of their employees, makes any warranty, express or implied, or assumes any legal liability or responsibility for the accuracy, completeness, or usefulness of any information, apparatus, product, or process disclosed, or represents that its use would not infringe privately owned rights. Reference herein to any specific commercial product, process, or service by trade name, trademark, manufacturer, or otherwise, does not necessarily constitute or imply its endorsement, recommendation, or favoring by the United States Government or any agency thereof. The views and opinions of authors expressed herein do not necessarily state or reflect those of the United States Government or any agency thereof. 


\title{
BTO Project 1.2.2.70 \\ FY19 2 ${ }^{\text {nd }}$ Quarter Milestone Report
}

\section{Annual Energy Savings and Peak Power Reduction Simulated for CCHP Design and Baseline HP in Cold Climate Cities}

\author{
Author \\ Bo Shen \\ Jeffrey Munk
}

Date: 02/28/2019

\author{
Prepared by \\ OAK RIDGE NATIONAL LABORATORY \\ Oak Ridge, TN 37831-6283 \\ managed by \\ UT-BATTELLE, LLC \\ for the \\ US DEPARTMENT OF ENERGY \\ under contract DE-AC05-00OR22725
}




\section{Annual Energy Savings and Peak Power Reduction Simulated for CCHP Design and Baseline HP in Cold Climate Cities \\ (Regular Milestone)}

\section{Executive Summary}

This report assesses energy savings and peak power reduction of three heat pumps in multiple US cold climate cities and building types. The three heat pumps comprise a baseline heat pump and two high efficiency cold climate heat pumps (CCHP). The DOE/ORNL Heat Pump Design Model was used to simulate the heat pumps and generate performance curves for EnergyPlus building energy simulations. The annual energy simulations were performed over seven cold climates: 1) Minneapolis, MN; 2) Duluth, MN; 3) Fairbanks, AK; 4) Helena, MT; 5) Indianapolis, IN; 6) Peoria, IL and 7) Eagle County, CO. In order to assess impact of residential building types matching different energy codes, we simulated six single-family houses in Indianapolis, IN, including : 1) single-family house having a crawlspace; 2) having a slab foundation; 3) having a heated basement; 4) having an unheated basement; 5) one single-family house having a heated basement matching IECC code of 2009, 6) and one single-family house having a heated basement matching IECC code of 2012. The former 4 houses match the IECC 2006 code.

The analyses demonstrate:

1. In heating load dominated houses where the heating load is 2 times to the cooling load and the heating energy consumption is 5 times larger, improvement in cooling operation efficiency is not important. Design improvement and cost increment should be focused on heating performance. If necessary, it is worthwhile to sacrifice the cooling performance for the advantage of heating operation, e.g. optimizing the system charge for heating than cooling, and accepting a low SEER but high HSPF heat pump, etc.

2. The two the CCHPs lead to peak power reduction from $10 \%$ to $20 \%$ and achieve $17 \%$ to $26 \%$ annual energy savings. In colder climate cities, the energy reduction ratios are lower, however, their absolute savings are higher.

3. Newer houses, e.g. matching 2012 IECC code, have more balanced cooling and heating loads, and require less resistance heat use in winter. Thus, the CCHPs lead to higher ratios of peak power reduction and energy savings in the newer houses. On the other hand, the absolute savings in the newer houses are lower, because the total energy consumption is less.

4. In the seven cold climate cities, 5-year operation cost savings of the two CCHPs are all higher than $\$ 500$ per unit of the rated cooling tonnage. In the coldest cities of Duluth and Fairbanks, the savings are about $\$ 1000$. These are very significant cost reductions, considering a heat pump price per unit of rated cooling tonnage is generally less than $\$ 1000$. Hence, the 5-year cost savings can amount to $50 \%$ to $100 \%$ of the unit price. It indicates that a high efficiency CCHP will easily achieve a 5-year payback period. 


\section{TABLE OF CONTENTS}

Page

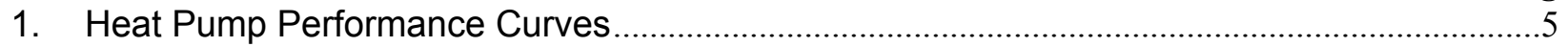

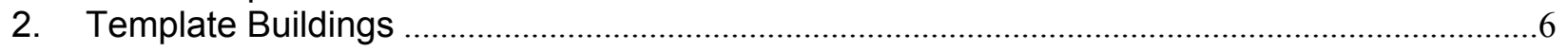

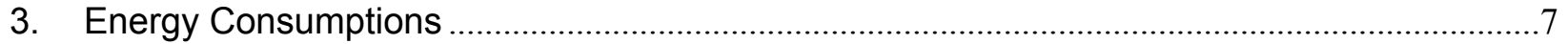

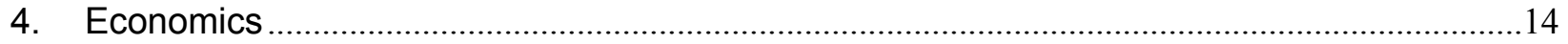

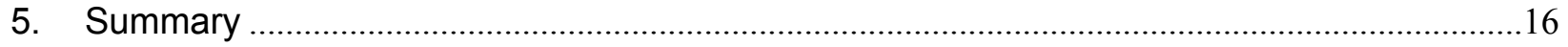

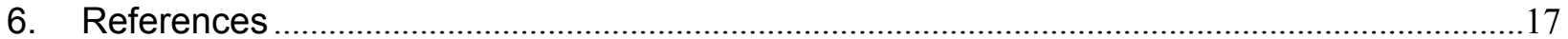




\section{List of Figures}

Figure 1: Heating COPs as a fuction of ambient temperature, for different designs and compressor stages

Figure 2: Building design cooling load, i.e. rated cooling capacites of heat pumps, according to various building types and energy standards in Indianapolis, IN

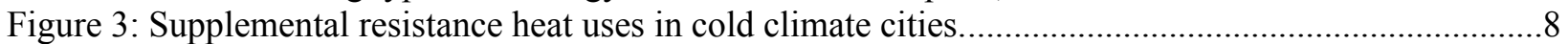

Figure 4: Peak power reductions in cold climate cities. ........................................................................

Figure 5: Heating seasonal electricity consumption ratios of tandem and 3-stage heat pumps, relative to the baseline heat pump in cold climate cities....

Figure 6: Cooling seasonal electricity consumption ratios of tandem and 3-stage heat pumps relative to the baseline heat pump in cold climate cities.....

Figure 7: Ratios of heating load to cooling load in multiple US cities..............................................10

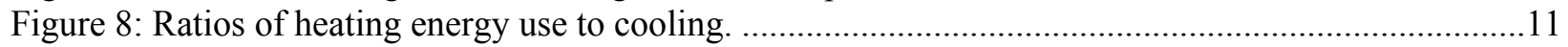

Figure 9: Total annual electricity consumption ratios of tandem and 3-stage heat pumps relative to the baseline heat pump in cold climate cities..............................................................................11

Figure 10: Average heating seasonal performance factors in cold climate cities, calculated by

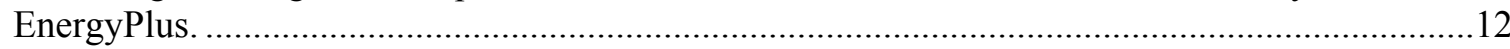

Figure 11: Supplemental resistance heat uses of various single-family houses in Indy..........................12

Figure 12: Peak power reductions of various single-family houses in Indy...........................................13

Figure 13: Heating seasonal performance factors in various single-family houses, calculated by EnergyPlus.

Figure 14: Energy consumption ratios to the baseline heat pump in various single-family houses,

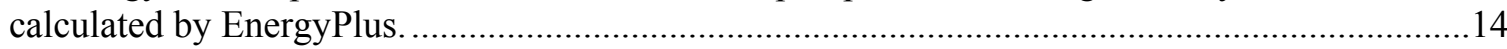

Figure 15: Ratios of heating load to cooling load of different building types in Indiapolis......................14

Figure 16: 5-year electricity cost savings in seven cold climate cities. ...............................................16

Figure 17: 5-year electricity cost savings of six single-family houses in Indianapolis. ...........................16 


\section{LIST OF TABLES}

Table 1: Annual electricity consumptions and savings of multiple cold climate cities .15

Table 2: Annual electricity consumptions and savings of multiple building types in

Indianapolis 


\section{Heat Pump Performance Curves}

EnergyPlus building energy simulations were performed to calculate annual energy savings and peak power reduction, based on the normalized performance curves produced by the DOE/ORNL Heat Pump Design Model [2], which simulated three heat pump designs as below:

- Baseline heat pump: it uses a single speed compressor. The compressor has nominal capacity of 51 $\mathrm{kBtu} / \mathrm{hr}$ and the heat pump has a rated cooling capacity at $54 \mathrm{kBtu} / \mathrm{hr}$. It achieves $14.0 \mathrm{SEER} / 9.3 \mathrm{HSPF}$ (DHRmin at Region IV, following AHRI 210/240 [1]). The system uses a TXV for cooling and another TXV for heating. The refrigerant charge is optimized for cooling mode, which causes over-charged during heating operation. The resultant subcooling degree reaches around $25 \mathrm{R}$ to $30 \mathrm{R}$. The subcooling degree leads to high compressor discharge temperature, and the compressor will be shut off below 0 ${ }^{\circ} \mathrm{F}$. It uses a single-speed indoor blower having a fan efficiency of $30 \%$.

- Tandem heat pump: this unit uses tandem compressors, i.e. two parallel, identical, single-speed compressors, coupled with a two-speed indoor blower. Each single-speed compressor has a nominal capacity of $31 \mathrm{kBtu} / \mathrm{hr}$. The tandem heat pump gets its rated cooling capacity (the building design cooling load) with a single compressor. The second compressor kicks in only for enhanced heating at low ambient temperatures, and not used for cooling and heating at ambient temperatures above $20^{\circ} \mathrm{F}$. The indoor fan efficiency is $30 \%$. It uses the same chassis, indoor and outdoor heat exchangers as the baseline. It has a TXV in cooling mode and an EXV for compressor discharge pressure control in heating mode. The heat pump is able to operate down to $-22^{\circ} \mathrm{F}\left(-30^{\circ} \mathrm{C}\right)$. It should be noted that the tandem compressors are optimized for heating operation. The heat pump has 15.0 SEER/11.2 HSPF and its rated cooling capacity is $36 \mathrm{kBtu} / \mathrm{hr}$.

- 3-stage heat pump: The third is a cost-optimized CCHP and has better cooling performance, which uses a 3-stage compressor and a two-speed indoor blower. The compressor stages are split to $50 \% / 67 \% / 100 \%$, having the top nominal capacity at $51 \mathrm{kBtu} / \mathrm{hr}$. The heat pump is rated at the $67 \%$ compressor capacity to get its rated cooling capacity, and the $100 \%$ compressor is used for enhanced heating at ambient temperatures below $20^{\circ} \mathrm{F}$. During cooling mode, the heat pump only operates its $50 \% / 67 \%$ compressor capacities, coupled with a TXV. During heating mode, an EXV is used to control the head pressure. The indoor blower has high efficiency at 50\%. It uses the same indoor and outdoor heat exchangers as the baseline. The heat pump has a rated cooling capacity is $42 \mathrm{kBtu} / \mathrm{hr}$, and achieves 16.0 SEER/12.0 HSPF.

One key feature of a CCHP is that the compressor(s) only use partial capacity to meet the design cooling load, while release its full capacity to meet the top heating load. Regarding the three heat pumps, the 
overcapacity ratios at low ambient temperatures are ranked as: tandem $-100 \% / 50 \%=2.0$, 3-stage compressor: $100 \% / 67 \%=1.49$, and baseline single-speed heat pump: $100 \% / 100 \%=1.0$.

Figure 1 compares heating COPs at various speed levels of the three heat pumps, simulated using HPDM. The baseline (14.0 SEER/9.3 HSPF) has the lowest efficiency, while the tandem heat pump at the low stage has the highest COP. The COP curves of the 3-stage heat pump running the low stage and middle stage are ranked at the second and third places at the ambient temperatures above $35^{\circ} \mathrm{F}$. It should be noted that the 3-stage heat pump running at the top stage below $35^{\circ} \mathrm{F}$ achieves even higher COPs than its two lower stages. The 3-stage compressor was optimized at the top stage, and efficiency degradation tends to happen at low modulation levels, which gets worse with lowering the ambient temperature and increasing the compression pressure ratio. The tandem heat pump is not subjected to this degradation, because each individual compressor was optimized on its own. The 3-stage heat pump at its top stage has the highest COP at extremely low ambient temperatures, because its top capacity is $20 \%$ smaller than that of the tandem compressors, while having the same heat exchangers.

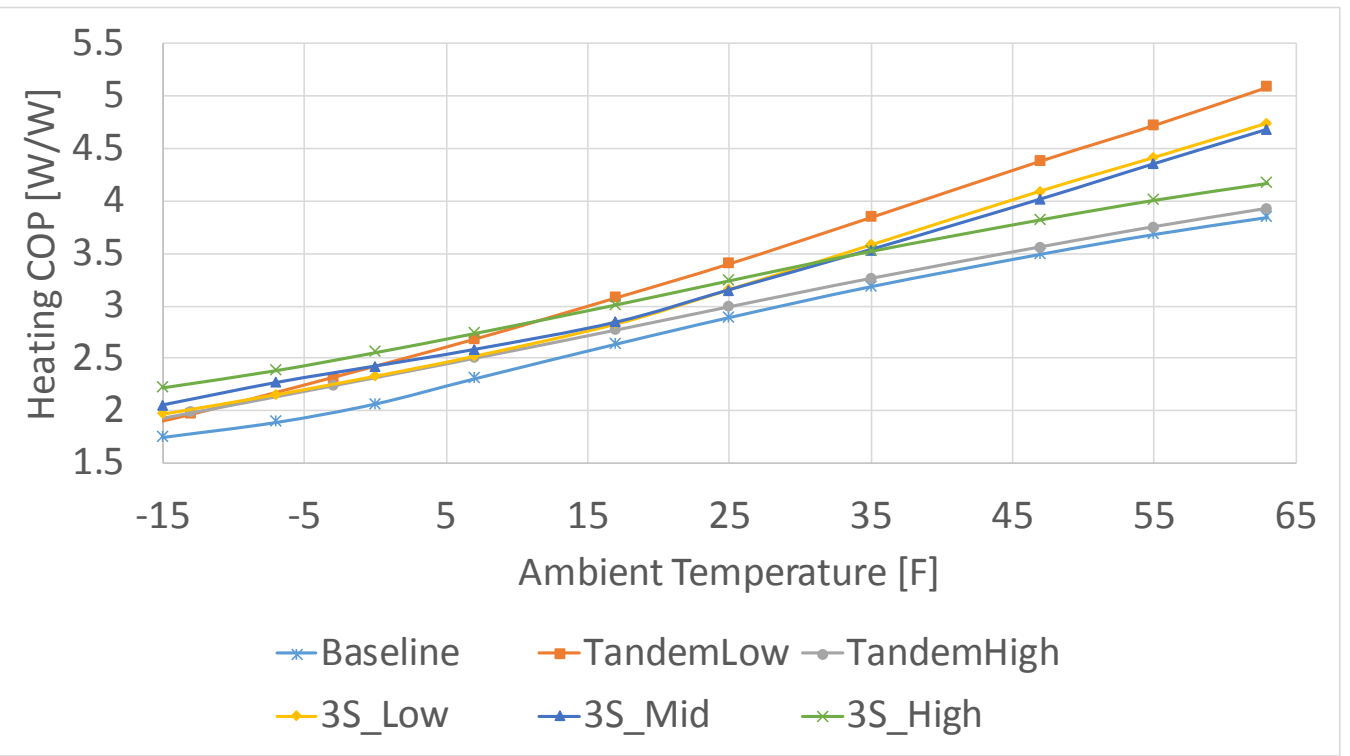

Figure 1: Heating COPs as a fuction of ambient temperature, for different designs and compressor stages

\section{Template Buildings}

To assess heat pump energy consumptions in various cold climate cities, we selected one residential single-family detached house with heated basement for the building simulations. The input files of the residential, single-family house were converted from Residential Prototype Building Models (developed by PNNL [3]), for seven cities: 1) Minneapolis, MN; 2) Duluth, MN; 3) Fairbanks, AK; 4) Helena, MT; 5) 
Indianapolis (Indy), IN; 6) Peoria, IL and 7) Eagle County, CO. The residential houses have one split heat pump. We intended the residential building case to represent a retrofit application, and thus, the building envelope characteristics were chosen to match requirements in the 2006 International Energy Conservation Code (IECC 2006) [3]. In heating season, the zone temperatures are uniformly controlled at $70^{\circ} \mathrm{F}$. In cooling season, the zone temperatures ae controlled at $75^{\circ} \mathrm{F}$.

To assess energy consumptions in multiple building types, six residential building templates in Indianapolis were selected: 1) single-family house having a crawlspace; 2) having a slab foundation; 3) having a heated basement; 4) having an unheated basement. The former 4 houses match the IECC 2006 code. To assess the impact of different energy codes, two more houses were simulated: 5) one single-family house having a heated basement matching IECC code of 2009, 6) and one single-family house having a heated basement matching IECC code of 2012. Figure 2 presents rated cooling capacities of the six singlefamily houses in Indianapolis. Clearly, the houses matching the 2009 and 2012 IECC codes require smaller capacities, indicating their better thermal insulation.

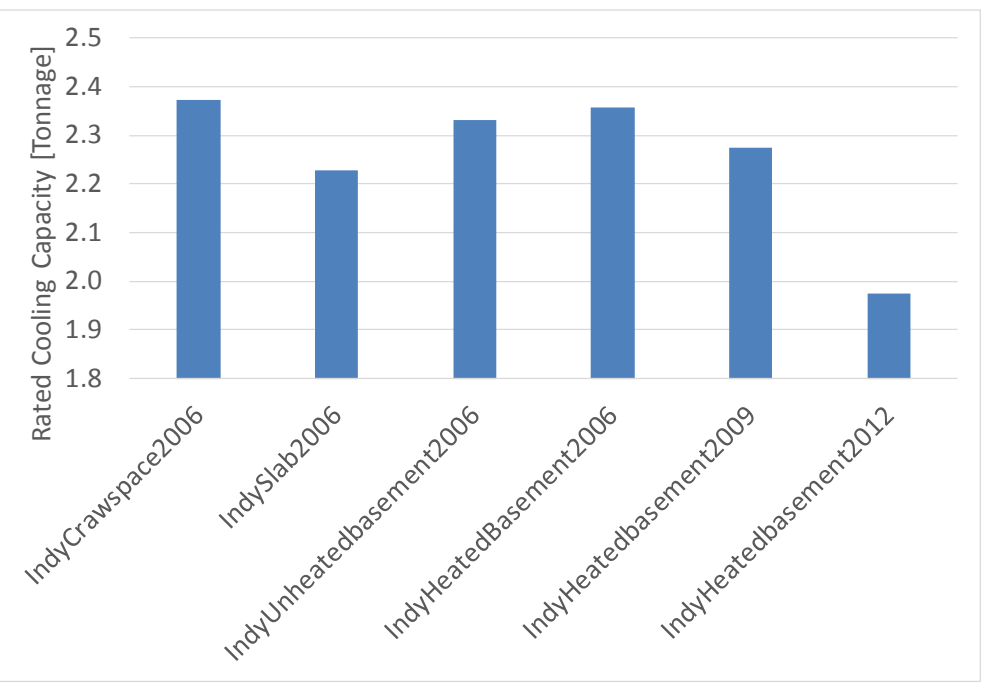

Figure 2: Building design cooling load, i.e. rated cooling capacites of heat pumps, according to various building types and energy standards in Indianapolis, IN.

To match the buildings and cold climate zones, the three heat pumps were auto-sized at the rated compressor stage for cooling operation, to match the building design cooling load. A supplemental resistance heater assists the heat pump to deliver adequate heating capacity and always meet the zone temperature setting in each single-family house.

\section{Energy Consumptions}

$\underline{\text { Compare cold climate cities }}$ 
Residential buildings matching the IECC 2006 code represent inadequately-insulated old houses. So, in the seven cold climate cities, when a heat pump was sized to match the building cooling load, substantial supplemental resistance heating is needed in winter. Figure 3 illustrates percentage of resistance heat uses for the three heat pumps. The colder climates result in higher supplemental resistance heat uses. The tandem configuration has higher overcapacity potential and thus leads to smallest percentages of supplemental heat.

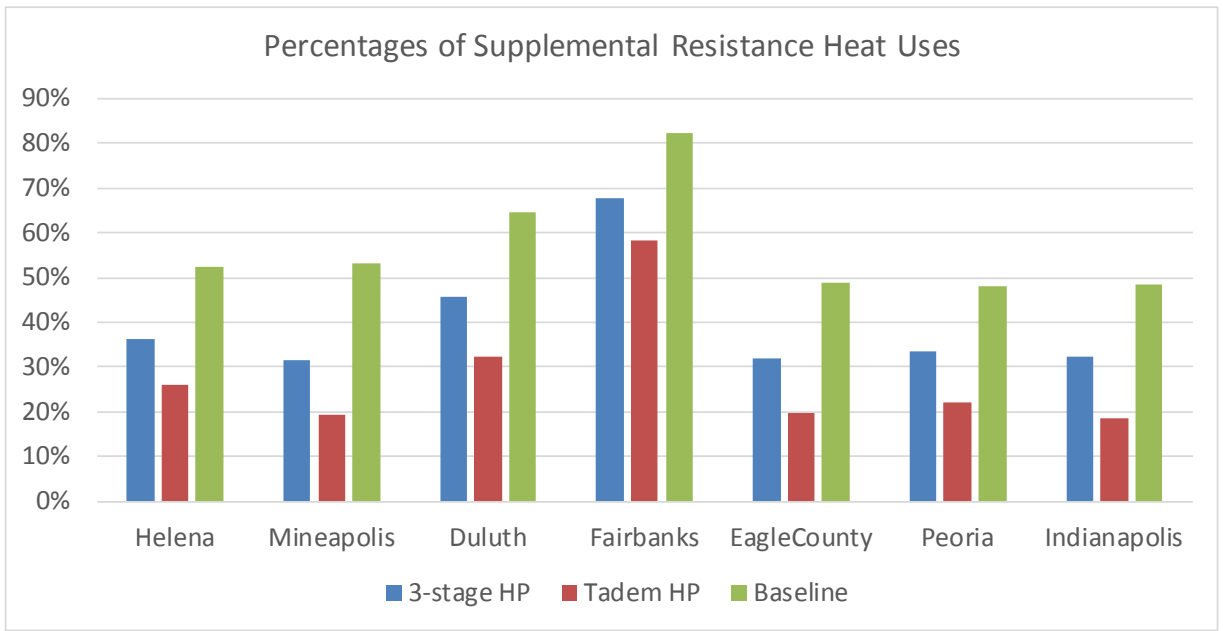

Figure 3: Supplemental resistance heat uses in cold climate cities.

Figure 4 shows peak power reduction. Because the baseline heat pump is shut off below $0^{\circ} \mathrm{F}$, above the peak heating outdoor temperatures of all the cities, it has no peak power reduction. The tandem and 3-stage CCHPs are turned off below $-22^{\circ} \mathrm{F}$, which result in no peak power duction in Duluth and Fairbanks where the extreme temperature go below $-30^{\circ} \mathrm{F}$. In other cities, the CCHPs lead to peak power reduction from $10 \%$ to $20 \%$.

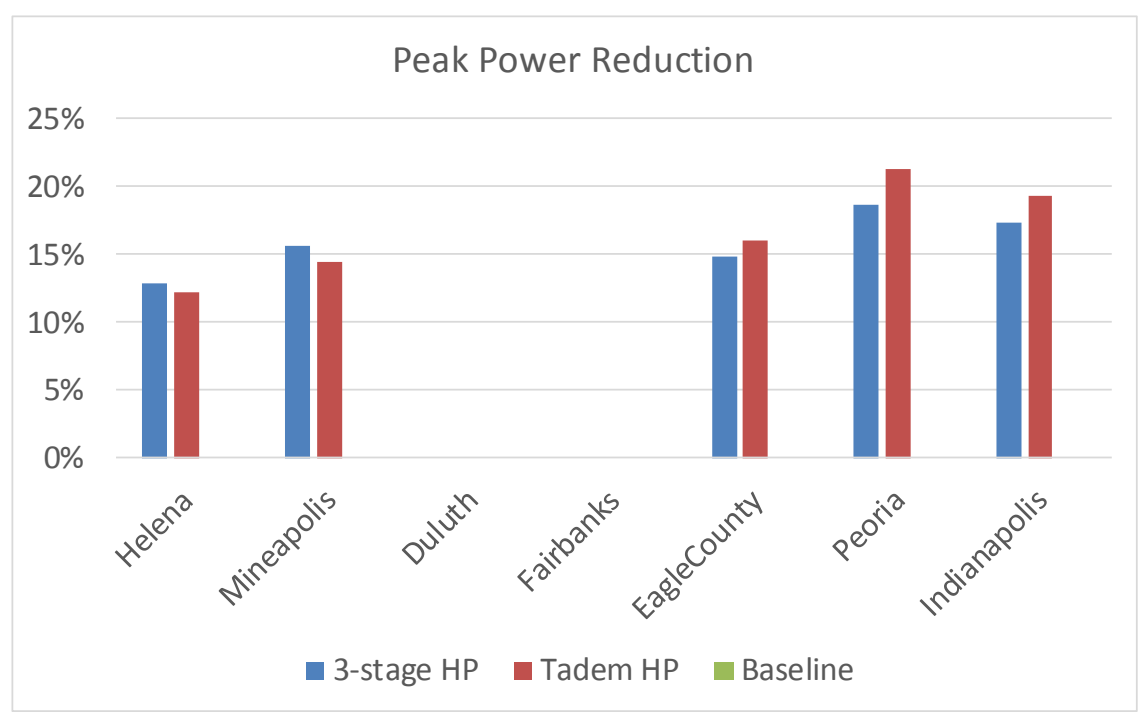

Figure 4: Peak power reductions in cold climate cities. 
Figure 5 depicts heating seasonal electricity consumption ratios of the tandem and 3-stage heat pumps, relative to the baseline, single-speed heat pump. In warmer cities, the energy reduction ratios are larger than colder cities. However, the absolute energy savings of $\mathrm{kWh}$ is more significant in colder cities, as indicted in Table 1.

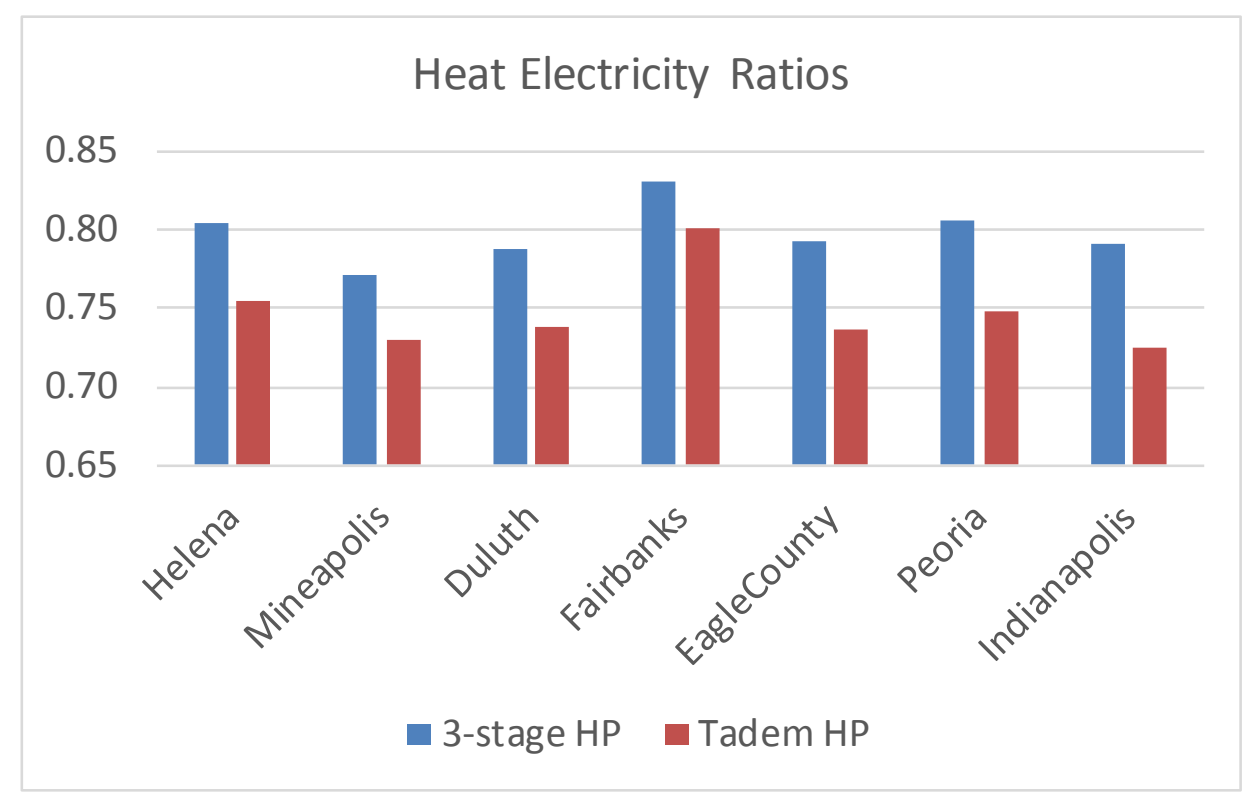

Figure 5: Heating seasonal electricity consumption ratios of tandem and 3-stage heat pumps, relative to the baseline heat pump in cold climate cities.

Figure 6 illustrates cooling seasonal electricity consumption ratios of the tandem and 3 -stage heat pumps relative to the baseline, single-speed heat pump. The 3-stage heat pump is the most efficient in cooling mode. 


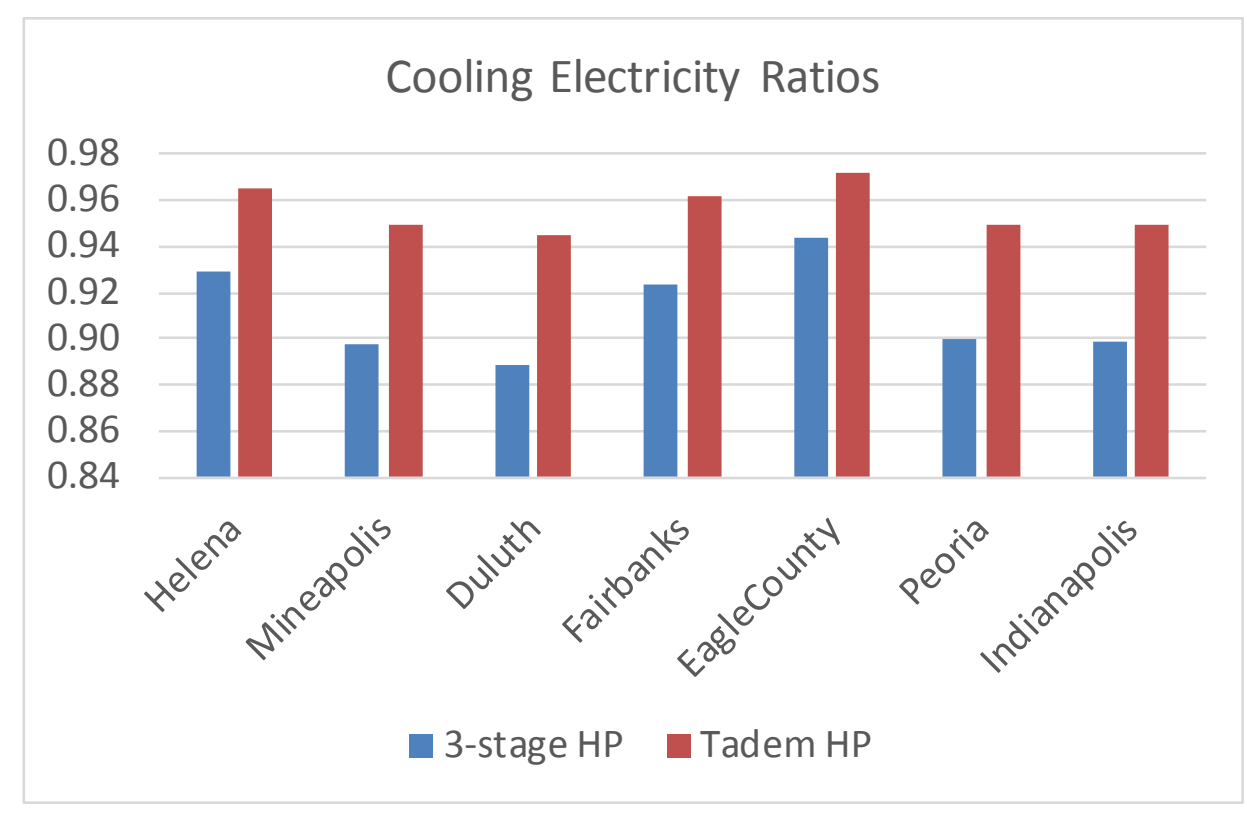

Figure 6: Cooling seasonal electricity consumption ratios of tandem and 3-stage heat pumps relative to the baseline heat pump in cold climate cities.

Figures 7 and 8 present building total heating load relative to its cooling load, total heating energy use when running the baseline heat pump relative to its cooling, respectively. The houses in the cold climate cities are dominated by heating load, where the load ratios are larger than 2.0 and energy consumption ratios are larger than 5.0. Consequently, the tandem heat pump reduces the annual total energy uses, more than the 3-stage heat pump, although it is less efficient in cooling mode. In the heating load dominated cities where the heating load is 2 times to the cooling load and the heating energy consumption is 5 times larger, improvement in cooling operation efficiency is not important.

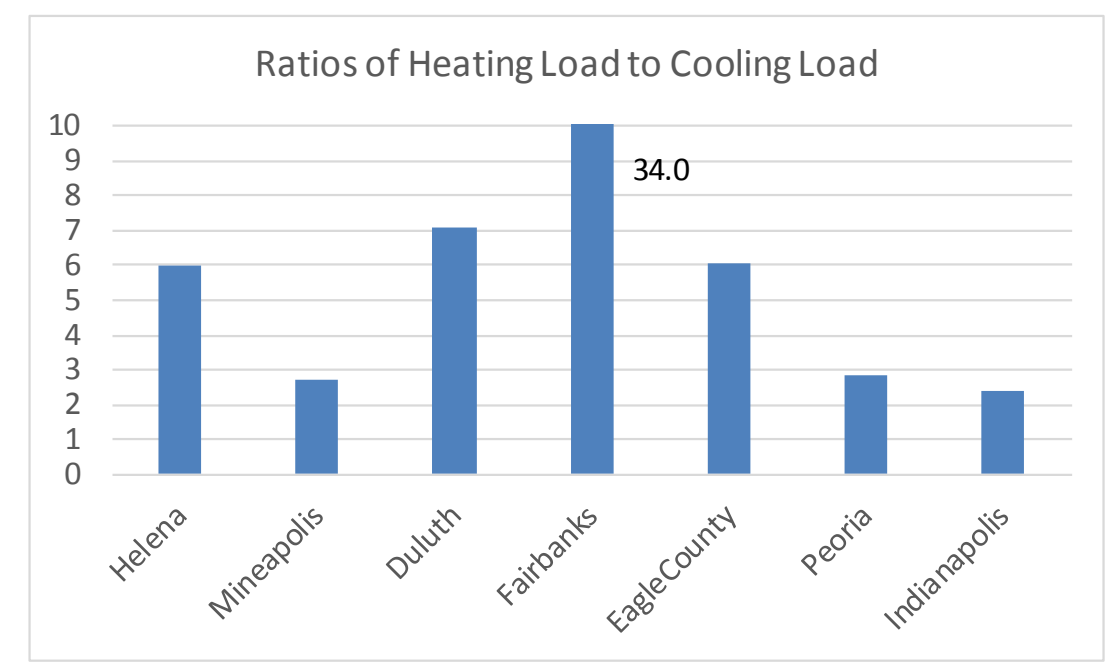

Figure 7: Ratios of heating load to cooling load in multiple US cities. 


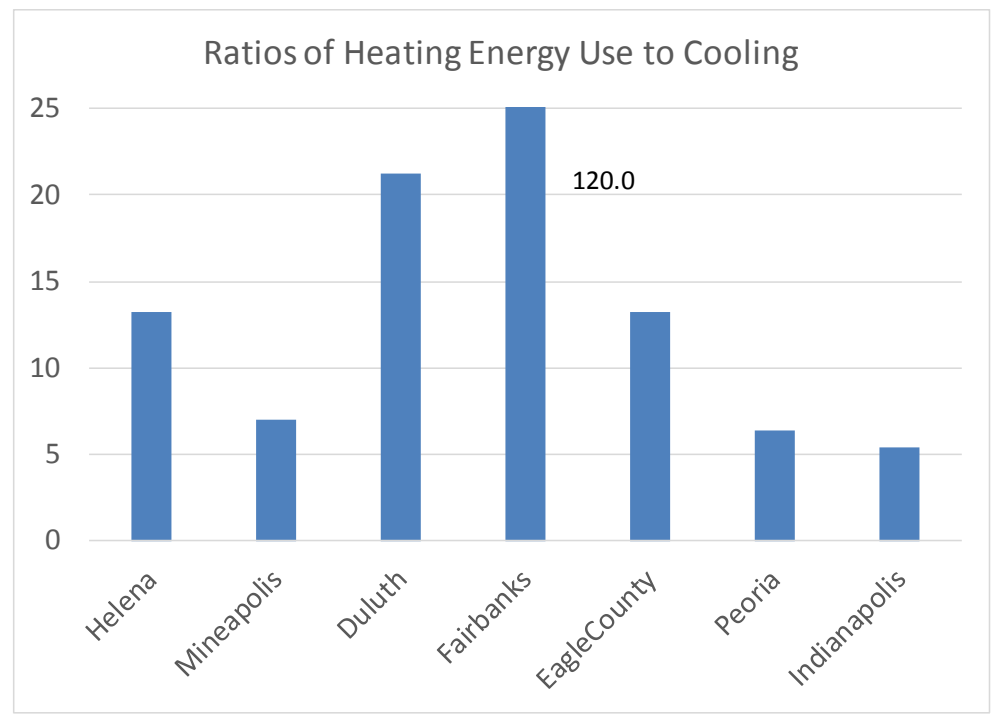

Figure 8: Ratios of heating energy use to cooling.

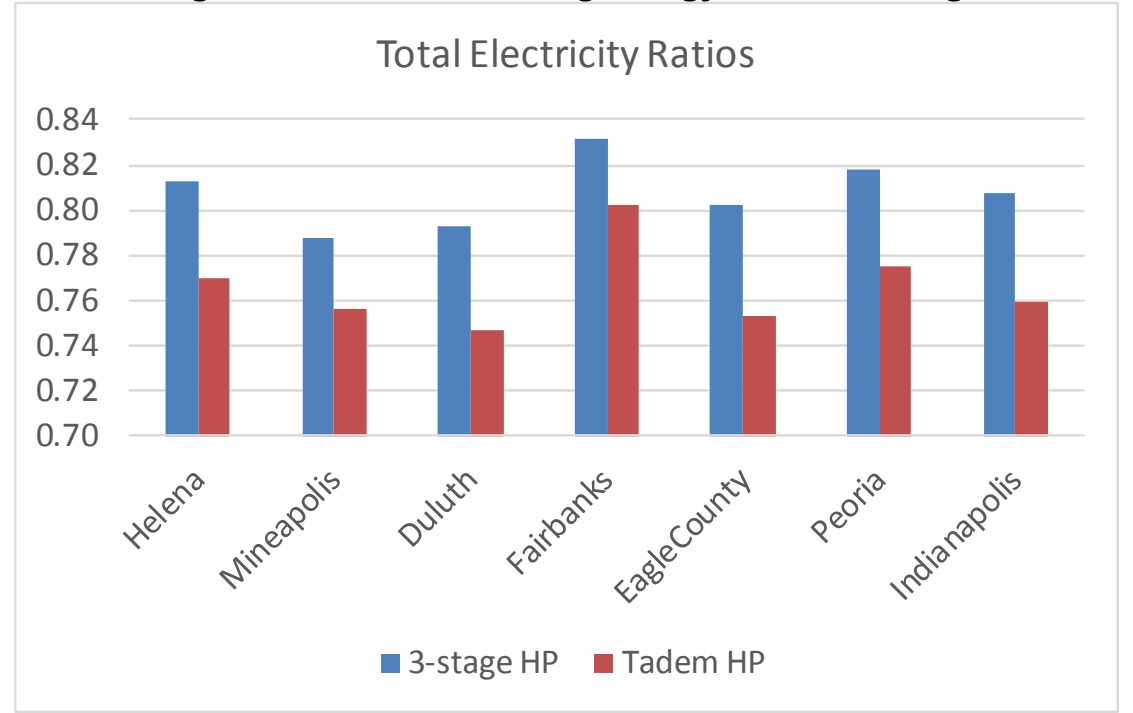

Figure 9: Total annual electricity consumption ratios of tandem and 3-stage heat pumps relative to the baseline heat pump in cold climate cities.

Figure 10 gives the average heating seasonal performance factors, calculated from the EnergyPlus building energy simulations. The tandem heat pump has the highest HSPFs in all the cities, higher than the 3-stage heat pump. This contradicts to the HSPF calculated following the AHRI 210/240 standard, which predicted a 11.2 HSPF for the tandem HP and 12.0 HSPF for the 3-stage heat pump. In AHRI 210/240, measured heating performance data above $17^{\circ} \mathrm{F}$ ambient are required. Below $17^{\circ} \mathrm{F}$, the heating performance is calculated using linear extrapolation, from the measured data at $17^{\circ} \mathrm{F}$ and $47^{\circ} \mathrm{F}$. This doesn't give enough credit to the heat pumps having larger overcapacity potential at ambient temperatures below $17^{\circ} \mathrm{F}$. 


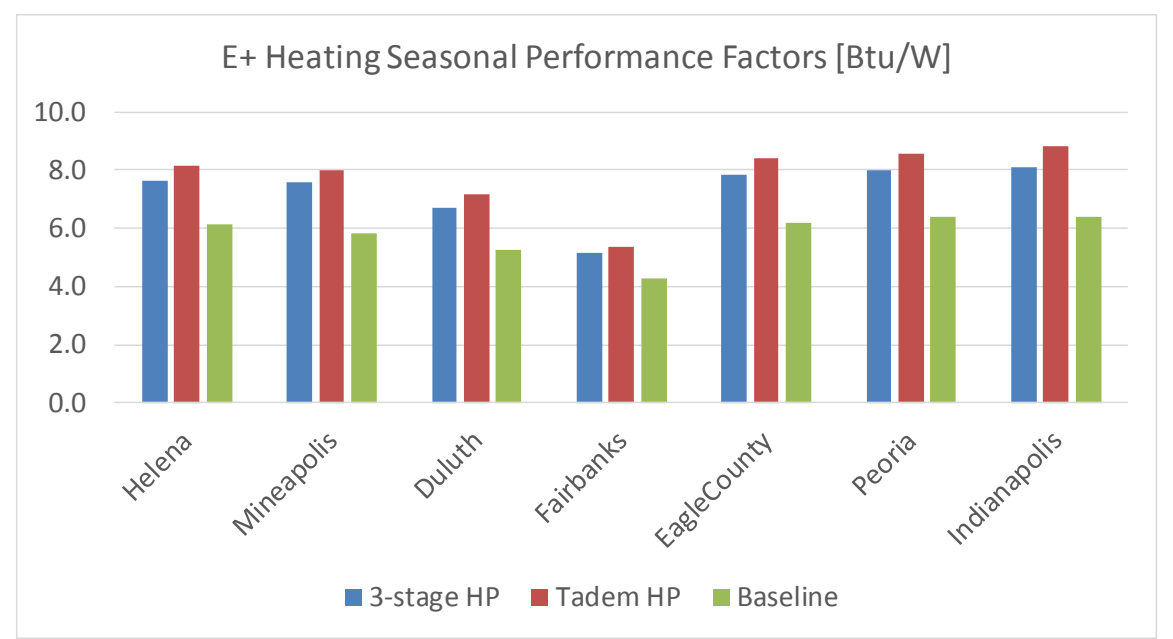

Figure 10: Average heating seasonal performance factors in cold climate cities, calculated by EnergyPlus.

Compare building types and energy codes

Figure 11 illustrates supplemental resistance heat uses of the six building types in Indianapolis. Clearly, the single-family house matching the 2012 IECC code has the lowest resistance heat use, and the one matching the 2009 IECC code is the second lowest. As a result, the newer houses lead to higher peak power reduction, as shown in Figure 12.

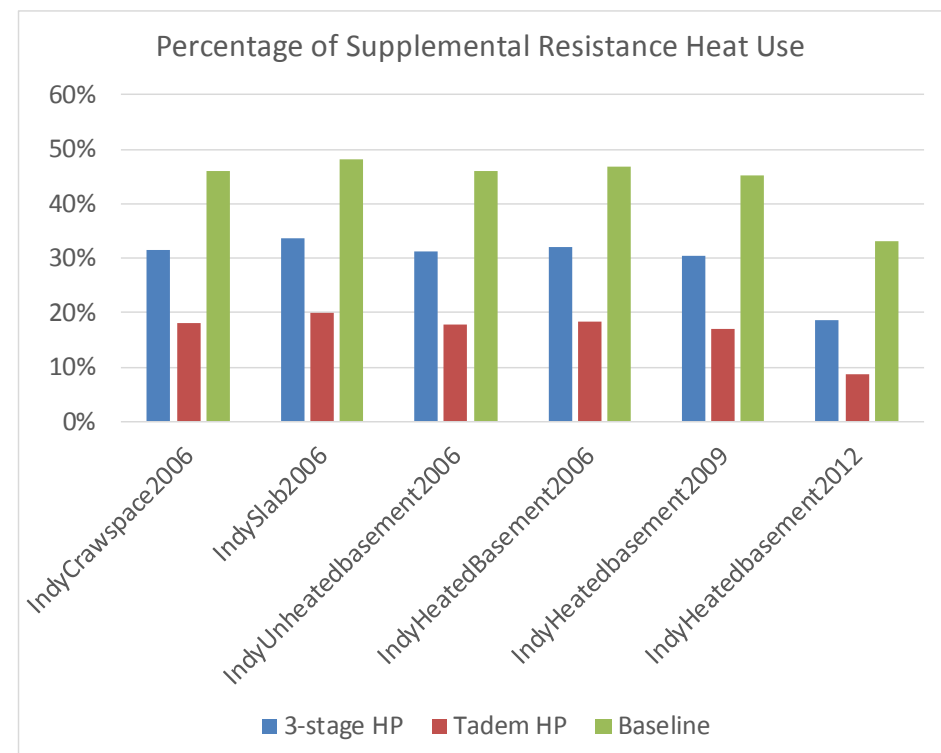

Figure 11: Supplemental resistance heat uses of various single-family houses in Indy. 


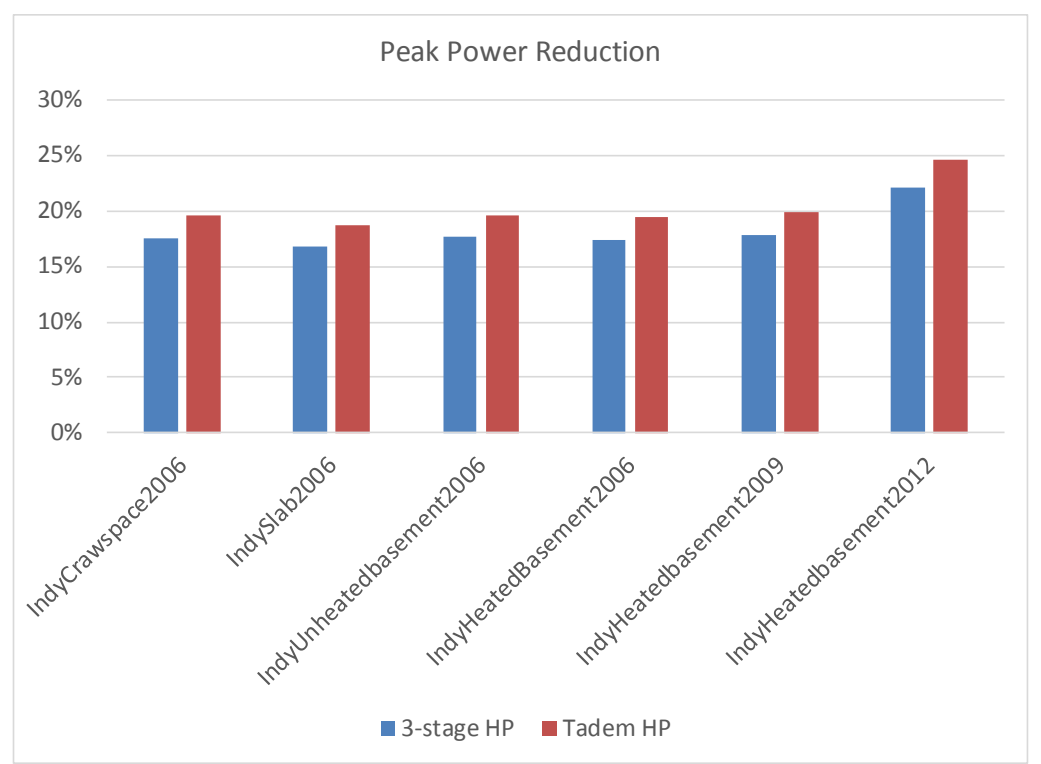

Figure 12: Peak power reductions of various single-family houses in Indy.

Figure 13 presents the heating seasonal performance factors calculated from the EnergyPlus simulations. The house matching the 2012 IECC code has the highest HSPFs because of its lower supplemental resistance heat use.

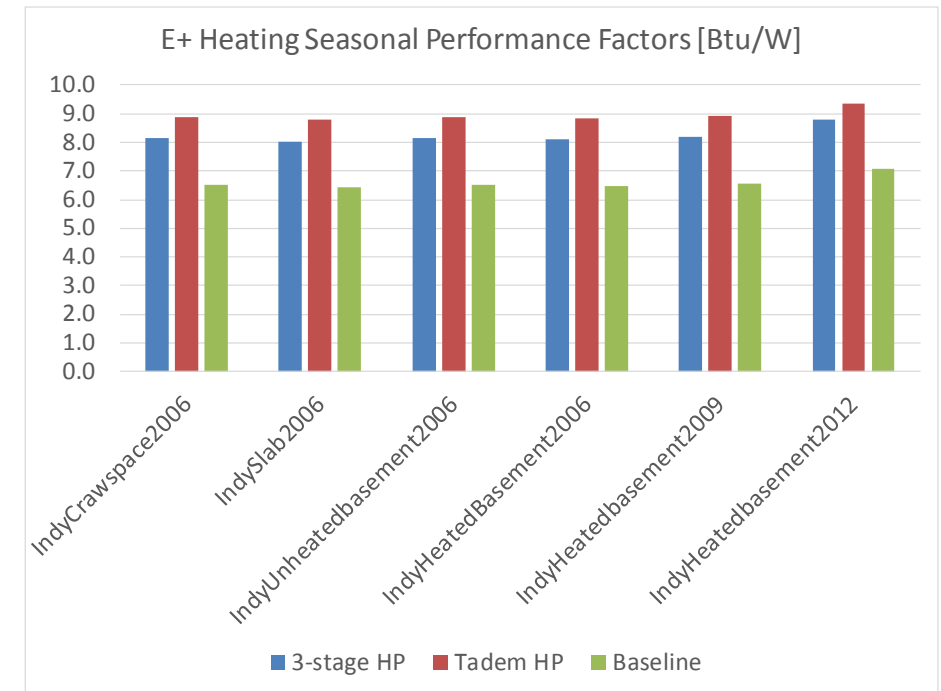

Figure 13: Heating seasonal performance factors in various single-family houses, calculated by EnergyPlus.

Figure 14 presents electricity consumption ratios, relative to the baseline, in terms of cooling season, heating season and total annually, with respect to the tandem and 3-stage heat pumps, respectively. The total electricity consumptions of the 3-stage and tandem heat pumps match each other in the well-insulated house of 2012. Figure 15 depicts the ratio of total delivered heating capacity (heating load) to the total delivered cooling capacity (cooling load). In the house matching the 2012 IECC code, the ratio is 1.5, 
indicating that the heating and cooling loads are more balanced. Thus, the efficiency enhancement in cooling mode become as important as in heating mode. The higher cooling efficiency of the 3-stage heat pump makes up its lower efficiency in heating mode. As a result, the annual energy consumptions of the two CCHPs are comparable.

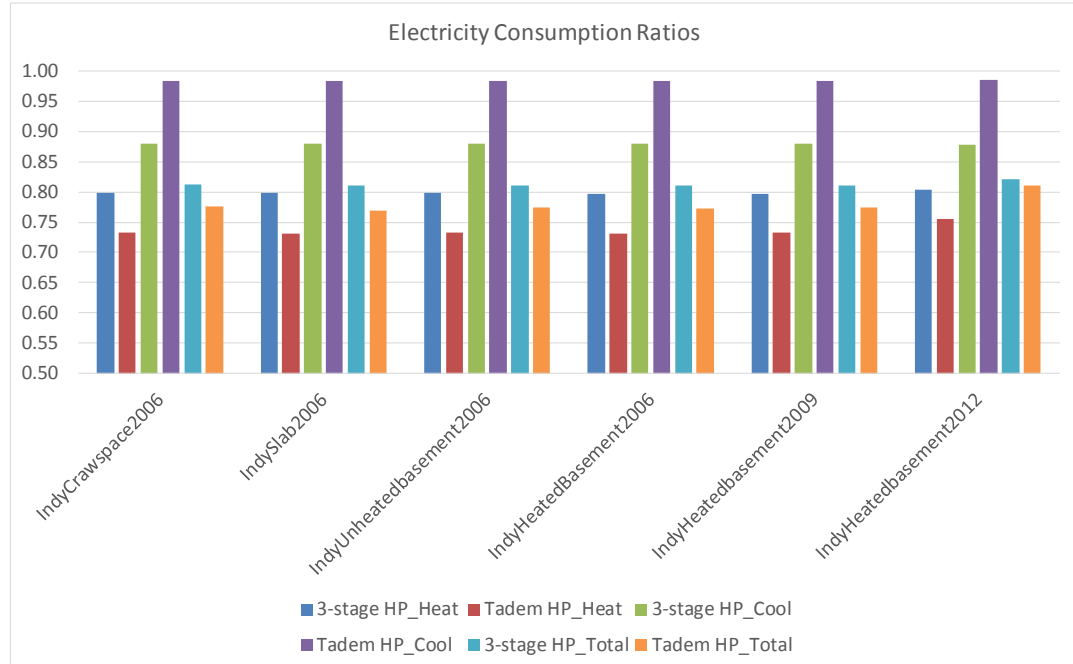

Figure 14: Energy consumption ratios to the baseline heat pump in various single-family houses, calculated by EnergyPlus.

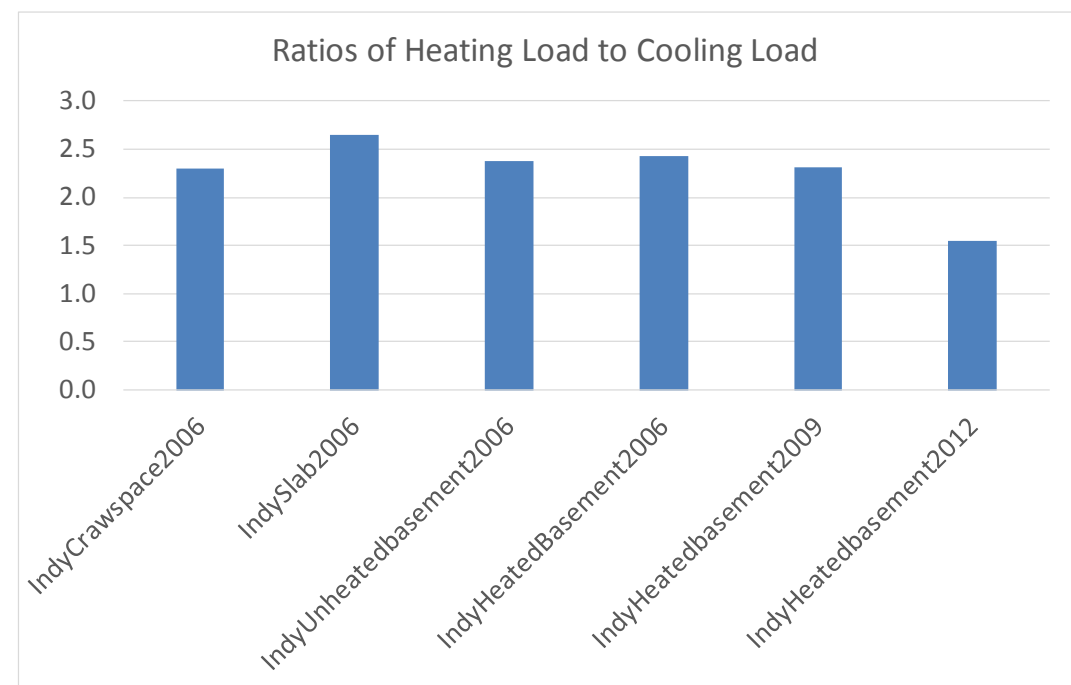

Figure 15: Ratios of heating load to cooling load of different building types in Indiapolis.

\section{Economics}

Table 1 reports total annual electricity consumptions [kWh] of the three heat pumps, and savings [kWh] versus the baseline heat pump, per unit of rated cooling tonnage (building design cooling load) in the seven cold climate cities. Although the colder cities, e.g. Duluth and Fairbanks, result in smaller energy reduction ratios, as indicated in Figure 9, they have the largest total energy consumptions and absolute savings. 
Table 1: Annual electricity consumptions and savings of multiple cold climate cities

\begin{tabular}{|c|c|c|c|c|c|c|c|}
\hline Total & Helena & Minneapolis & Duluth & Fairbanks & Eagle County & Peoria & Indianapolis \\
\hline 3 -stage & 4912.6 & 4501.5 & 6779.5 & 11710.5 & 4686.4 & 4474.3 & 4434.0 \\
\hline Tandem & 4653.8 & 4326.2 & 6385.4 & 11303.7 & 4399.3 & 4241.3 & 4173.5 \\
\hline Baseline & 6046.4 & 5716.6 & 8554.0 & 14087.2 & 5838.8 & 5472.5 & 5493.4 \\
\hline \multicolumn{8}{|c|}{$\mathrm{kWh}$ savings per unit of rated cooling tonnage } \\
\hline 3-stage & 1133.8 & 1215.1 & 1774.6 & 2376.7 & 1152.4 & 998.2 & 1059.4 \\
\hline Tandem & 1392.6 & 1390.4 & 2168.7 & 2783.5 & 1439.5 & 1231.2 & 1319.9 \\
\hline
\end{tabular}

Table 2 presents total annual electricity consumptions and savings [kWh] of the six single-family houses in Indianapolis. It is interesting to see that the high efficiency CCHPs result in more savings in inadequately insulated houses matching the IECC code of 2006. The 2012 house has the least absolute energy saving. It means that the high efficiency CCHPs will have shorter payback time if used in old houses.

Table 2: Annual electricity consumptions and savings of multiple building types in Indianapolis

\begin{tabular}{|c|c|c|c|c|c|c|}
\hline Total & IndyCrawspace2006 & IndySlab2006 & IndyUnheatedbasement2006 & IndyHeatedBasement2006 & IndyHeatedbasement2009 & IndyHeatedbasement2012 \\
\hline 3-stage & 4359.0 & 4569.5 & 4413.1 & 4436.5 & 4265.4 & 3281.9 \\
\hline Tandem & 4162.2 & 4330.5 & 4210.3 & 4224.7 & 4076.9 & 3241.1 \\
\hline Baseline & 5368.8 & 5635.2 & 5439.3 & 5474.2 & 5261.2 & 3994.9 \\
\hline \multicolumn{7}{|c|}{ kWh savings Per rated cooling tonnage } \\
\hline 3-stage & 1009.9 & 1065.7 & 1026.2 & 1037.7 & 995.8 & 713.0 \\
\hline Tandem & 1206.6 & 1304.7 & 1229.1 & 1249.4 & 1184.2 & 753.8 \\
\hline
\end{tabular}

Considering customers would most likely accept a payback period within 5 years and $1 \mathrm{kWh}$ electricity costs 10 cents, Figure 16 illustrates 5-year electricity cost savings resulted by the high efficiency CCHPs per unit of rated cooling tonnage, in the seven cities. The 5-year cost savings of the two CCHPs are all higher than \$500, with the tandem CCHP having 20\% more. In the coldest cities of Duluth and Fairbanks, the savings are about $\$ 1000$. These are very significant cost reductions, considering a typical heat pump price per rated cooling tonnage is generally less than $\$ 1000$. Hence, the 5-year cost savings can amount to $50 \%$ to $100 \%$ of the unit price. It indicates that a high efficiency CCHP will easily achieve a 5-year payback period.

Figure 17 illustrates 5-year electricity cost savings of the six houses in Indianapolis. The well-insulated home matching the 2012 IECC code has the lowest cost saving, while the CCHPs lead to more savings in less insulated houses. It indicates that the CCHPs in retrofit application will have shorter payback period. 


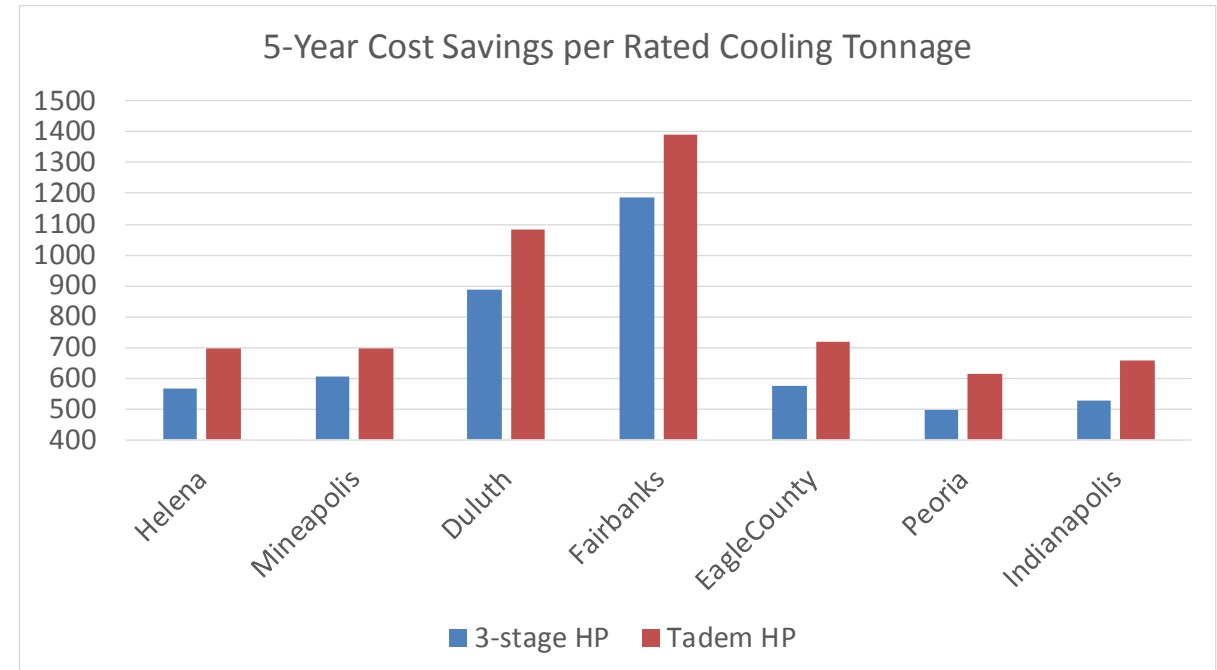

Figure 16: 5-year electricity cost savings in seven cold climate cities.

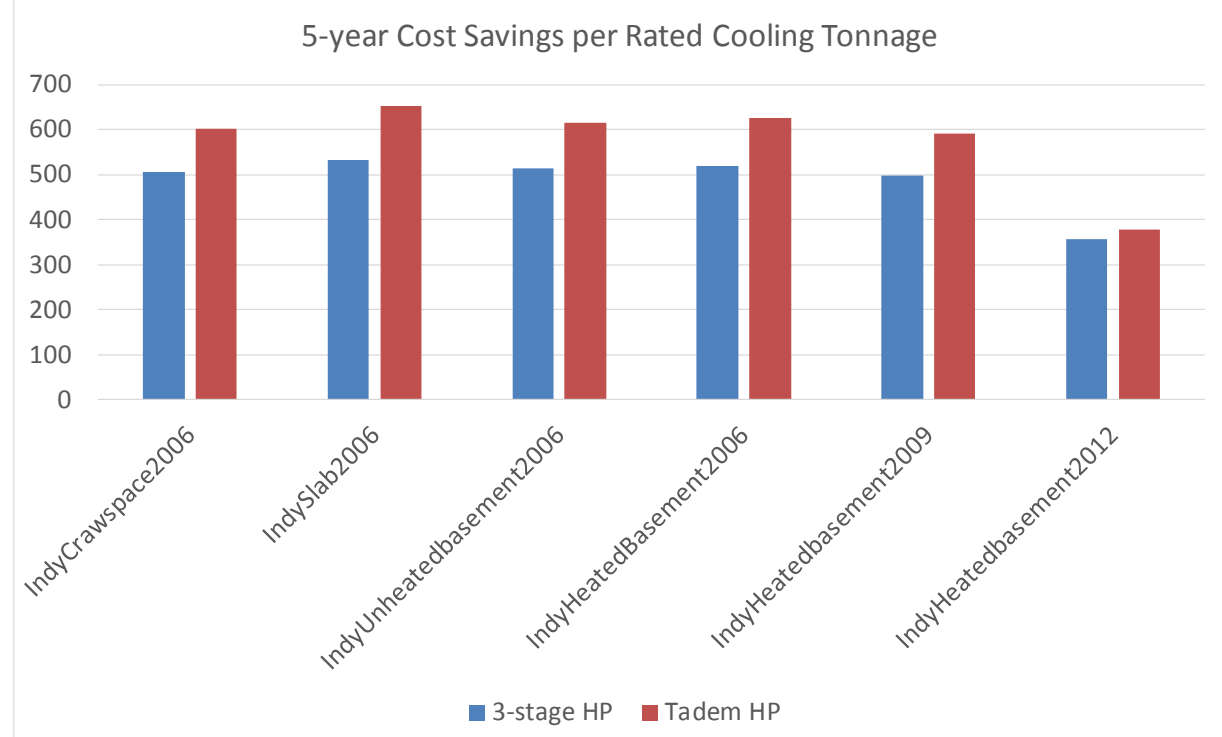

Figure 17: 5-year electricity cost savings of six single-family houses in Indianapolis.

\section{Summary}

It can be concluded:

1. In heating load dominated houses where the heating load is 2 times to the cooling load and the heating energy consumption is 5 times larger, improvement in cooling operation efficiency is not important. Design improvement and cost increment should be focused on heating performance. If necessary, it is worthwhile to sacrifice the cooling performance for the advantage of heating operation, e.g. optimizing the system charge for heating than cooling, and accepting a low SEER but high HSPF heat pump, etc. 
2. The two the CCHPs lead to peak power reduction from $10 \%$ to $20 \%$ and achieve $17 \%$ to $26 \%$ annual energy savings. In colder climate cities, the energy reduction ratios are lower, however, their absolute savings are higher.

3. Newer houses, e.g. matching 2012 IECC code, have more balanced cooling and heating loads, and require less resistance heat use in winter. Thus, the CCHPs lead to higher ratios of peak power reduction and energy savings in the newer houses. On the other hand, the absolute savings in the newer houses are lower, because the total energy consumption is less.

4. In the seven cold climate cities, 5-year operation cost savings of the two CCHPs are all higher than $\$ 500$ per unit of the rated cooling tonnage. In the coldest cities of Duluth and Fairbanks, the savings are about $\$ 1000$. These are very significant cost reductions, considering a heat pump price per unit of rated cooling tonnage is generally less than $\$ 1000$. Hence, the 5-year cost savings can amount to 50\% to $100 \%$ of the unit price. It indicates that a high efficiency CCHP will easily achieve a 5-year payback period.

\section{References}

[1] AHRI 2017. ANSI/AHRI Standard 210/240-2017, "Performance Rating of Unitary Air-Conditioning and Air Source Heat Pump Equipment," Air-Conditioning, Heating, and Refrigeration Institute, Arlington, VA, USA.

[2] DOE/ORNL Heat Pump Design Model: https:/hpdmflex.ornl.gov

[3] PNNL. 2012. Residential Prototype Building Models, Pacific Northwest National Laboratory, Richland, WA, USA, http://www.energycodes.gov/development/residential/iecc_models 